\title{
DESIGNING CONTRACTS FOR UNIVERSITY SPIN-OFFS
}

\author{
INÉS MACHO-STADLER \\ Department of Economics, CODE \\ XREA Barcelona Economics \\ Universitat Autònoma de Barcelona \\ 08193 Bellaterra, Spain \\ Ines.Macho@uab.es \\ DaVid PÉREZ-Castrillo \\ Department of Economics, CODE \\ XREA Barcelona Economics \\ Universitat Autònoma de Barcelona \\ 08193 Bellaterra, Spain \\ David.Perez@uab.es \\ ReINHILde VeugeleRs \\ Department of Applied Economics \\ Katholieke Universiteit Leuven \\ Naamsestraat 69, 3000 Leuven, Belgium \\ EC (BEPA), Brussels and CEPR, London \\ Reinhilde.Veugelers@econ.kuleuven.ac.be
}

We provide a theoretical model about how to design academic spin-off contracts between the university technology transfer office (TTO), the researcher, and the venture capitalist. The optimal contract entails the allocation of founder shares to the researcher to secure her participation in the venture. It may also require the researcher to be financially involved in the project to give her incentives to provide effort. We also show that when the TTO has better information than the other two participants concerning the likelihood of success of the spin-off, it will end up owning both founder and financial shares in the venture.

We are grateful to Paul van Dun, director of KULeuven R\&D and Rudy Cuyers for their detailed explanation of the functioning of university spin-offs at KUL. The authors thank the participants of the EARIE 2006 Conference (Amsterdam), the Jornadas de Economía Industrial (Barcelona), the Research Workshop in IO and Innovation (Barcelona), seminar attendants at the Colegio de Economistas, Queen Mary London, and Isles Balears for useful comments, and particularly Gerard Llobet, Mark Schankerman, the coeditor, and finally the referee. This research has been conducted thanks to the financial support of the Fundación BBVA. We also thank project SEJ2006-00538-ECON. The paper reflects only the views of the authors and does not commit the European Commission. 


\section{INTRODUCTION}

New technology ventures originating from basic research have the potential of introducing technological disequilibria that shake existing industries and form the gene pool from which new industries may emerge in the long run. Academic entrepreneurship in biotechnology and ICT are probably the most striking examples of this phenomenon (Zucker et al., 1998). Universities and public research institutes play an important role in this process, as they can be a breeding ground for new venture creation from basic research.

Although basic research results can be channeled to industry via either collaborative research schemes or licensing arrangements of patented university inventions, spinning off is the entrepreneurial route to commercializing public research. The latter have attracted a great deal of policy attention within the current wave of start-ups and new venture creation in many countries. The university spin-off formation rate is often seen as a key indicator of the quality of the industry-science links of a country or region. The general perception is that there is insufficient academic entrepreneurship. Policies are currently being designed to stimulate universities to be more effective in generating spin-offs. In the United States, commercial activities by academic institutes were stimulated by the Bayh-Dole act of 1980 and the 1986 Federal Technology Transfer Act (Mowery et al., 2001; Nelson, 2001). But also in Europe, policies have been introduced that strengthen the role of universities and academic spin-offs in innovation and growth (Geuna et al., 2003). In most EU countries, ownership of inventions generated by publicly funded research has been awarded to universities, giving them more leeway for commercialization.

Despite the huge amount of attention by policy makers, the scholarly debate on this issue is still inconclusive. The motives for creating spin-offs in innovative high-tech industries and the process governing their formation and success are still not well understood (Klepper, 2001). Although empirical studies in the economics and the management literature have attempted to quantify knowledge transfers from academic research in general using various proxies, ${ }^{1}$ several empirical papers have examined the emergence of academic spin-off activities more specifically. Most of this empirical literature is developing around the factors governing the emergence of academic spin-offs, such as the quality and nature of the research performed at the university as well as the entrepreneurial orientation and commitment of the university

1. Shane (2002) investigated the licensing of university-generated innovations. Henderson et al. (1998) and Mowery (1998) looked at citations to academic patents. Siegel et al. (2003) studied university science parks. 
to industry-science links (ISL), particularly through a professional technology transfer office and a proper incentive system for researchers (e.g., Audretsch and Stephan, 1996; Zucker et al., 1998; Nerkar and Shane, 2003; Chukumba and Jensen, 2005; Lockett and Wright, 2005). A limited number of empirical studies focus on the success rates of academic entrepreneurship. Although these studies typically produce mixed results (Lerner, 2004; Lowe and Ziedonis, 2006), they do show that the more successful spin-offs seem to be those with direct involvement of academic scientists (Zucker et al., 1998; Etzkowitz, 2002).

In the literature on start-ups and spin-offs, careful attempts at matching empirical results and economic theories are still at a pioneering stage. ${ }^{2}$ Although there has been a recent increase in empirical research, the theoretical literature on spin-offs remains underdeveloped.

In this paper, we provide a theoretical model for designing academic spin-off contracts between the university technology transfer offices (TTOs), the researcher, and the venture capitalist. More particularly, we study how the TTO, which owns the intellectual property, should allocate financial and founder (intellectual) shares in the venture, taking into account the participation constraint of both the star researcher and the venture capitalists, the moral hazard problem of researcher involvement in the spin-off, and the asymmetric information problem of the likelihood of success. Our main results are the following. The optimal contract entails the allocation of founder shares to the researcher to secure her participation in the venture. However, it may also require her to be financially involved in the project. Even if the unit cost of the capital provided by the venture capitalist is lower than the unit cost of the capital owned by the researcher, the allocation of financial shares to the latter may be the only way to make sure that she really has an incentive to put effort into the venture.

Given that it is inefficient for the TTO to finance part of the venture (as the cost of the capital is lower for the venture capitalist), the TTO takes no financial shares. It is the residual claimant of the relationship; hence it gets the founder shares that are left after providing the researcher with incentives to be involved in the spin-off, and after compensating both the venture capitalist and the researcher for their financial contributions.

The situation is different if, as we argue in the paper, the TTO has more accurate information than the other two participants concerning the likelihood of success for the spin-off. In this case, the TTO is forced

2. Chukumba and Jensen (2005) present a model explaining why a university invention is commercialized through a spin-off rather than through licensing. This happens when it is impossible to find a licensor. They also provide empirical analysis that indicates the university characteristics that explain whether licensing or spinning-offs appear (cf. infra). 
to "signal" profitable projects by taking financial stakes in them. Hence, it ends up owning both founder and financial shares in the ventures.

Because our model builds strongly on empirical evidence, particularly from the KULeuven experience, Section 2 summarizes the existing, mostly empirical, literature on academic spin-offs and details the KULeuven case. We discuss the model structure in Section 3 and present the results in Sections 4 and 5 for the case where all the agents involved have symmetric information concerning the value of the project. Section 6 analyzes the situation where the University TTO possesses more accurate information than the researcher and the venture capitalist about the expected value of the spin-off. Section 7 presents some empirical implications and some observations in support of our model results. All the proofs are included in an Appendix.

\section{ACADEMIC SPIN-OFFS: DETERMINANTS AND EFFECTS}

Significant research has recently been devoted to measuring and analyzing academic entrepreneurship (e.g., Zucker et al., 1998; Shane, 2002; Bartelsman et al., 2003). A number of empirical studies have investigated why certain universities are more successful than others in generating academic spin-offs. A decentralized model of technology transfer, through a dedicated and specialized TTO, characterizes most of the universities with a high record of ISLs (see Bercovitz et al., 2001, for the United States). In addition, Di Gregorio and Shane (2003) found the availability of venture capital funds, the commercial orientation of the university research, the intellectual eminence of the university, and its ISL policy all increased new firm formation significantly. With respect to ISL policy, equity investments by the university TTO in start-ups and a high share of royalties for the inventor were important catalysts. In addition, Lockett and Wright (2005) found empirical support for the importance of TTOs in spin-off formation, of particular importance were their personnel and spending on intellectual property rights, business development expertise, and attention to royalty regimes. O'Shea et al. (2005) found strong path dependence in predicting technology transfer activities by universities, although the size, the faculty quality, the orientation of science and engineering funding and, finally, the commercial capabilities of the institution also predicted university spin-offs.

The success and growth of academic spin-offs after the start-up phase has received less attention. The evidence on spin-off performance is mixed. Lowe and Ziedonis (2006) compare the outcomes of academic licenses to start-ups versus those to established firms. They find that royalty income from start-ups by universities is higher on average, 
but that successful commercialization only occurs after acquisition by an established firm. In addition, for a sample of MIT inventions, Shane (2002) finds that licenses to start-ups perform poorly compared to those where the licenses were allocated to established firms. A number of recent papers have further analyzed the performance of spin-offs as compared to other de novo start-ups and, within spinoffs, compared university-based ones to other types (e.g., Franco and Filson, 2000; Nerkar and Shane, 2003; Klepper and Sleeper, 2005). This literature has provided various predictions about the relative postentry performance of university and corporate spin-offs. It has taken into account such items as the nature of innovations and new products introduced by corporate spin-offs (imitation, innovation, differentiation from the parent organizations, etc.), and the linkages with their parent organizations (competition versus cooperation). For instance, Klepper and Sleeper (2005) show that in the U.S. laser industry, spin-offs have outperformed other start-ups. Link and Scott (2005) discuss spin-offs at university science parks, and Rothermael and Thursby (2005) discuss those developed at university incubators.

Compared to the recently growing empirical analysis of academic spin-offs, the theoretical analysis remains underdeveloped. Major issues facing universities in technology transfer are first whether researchers have sufficient incentives to disclose their inventions and second how to induce researchers' cooperation in further development. Although the Bayh-Dole act stipulates that scientists must file an invention disclosure, this rule is rarely enforced. Rather, for disclosure to materialize, the university needs to have proper incentive schemes in place, specifying an adequate share for the inventors in royalties or equity. This is studied for researchers' cooperation in commercializing through licensing in Macho-Stadler et al. (1996), Jensen and Thursby (2001), Dechenaux et al. (2003), and with respect to inventor disclosure, in Jensen et al. (2003). The importance of proper inventor royalty sharing rules for university performance in terms of disclosed inventions and license income is confirmed by Lach and Schankerman (2004). Analyzing panel data on U.S. universities they find that private universities with higher inventor shares have higher license incomes. All of these models focus on licensing rather than on commercialization through start-ups. Nevertheless, the empirical analysis of start-up creation by universities has shown that establishing royalty regimes is also important for improving the creation rate of academic spin-off (e.g., Lockett and Wright, 2005).

Even when disclosure is encouraged through appropriate incentive schemes, not all inventions will be patented and licensed by the university, which may have to, or prefer to, "shelve" inventions. This relates to another problem in the market for technology transfer, namely 
the asymmetric information between buyer and seller about the value of the innovations. Buyers typically cannot assess the quality of the invention ex ante, whereas researchers may find it difficult to assess the potential commercial profitability of their inventions. This problem is studied in Macho-Stadler et al. (2007), who use a reputation argument for an intermediary, such as a TTO, to alleviate the asymmetric information problem. Again this model studies licenses rather than development through spin-offs.

Aghion and Tirole (1994), using an incomplete contract framework, study how the allocation of property rights and possibly a sharing rule on profits, between a research unit on the one hand and his "client" who will use the invention (and/or venture capitalist), can be used to extract the optimal effort from the researcher and from the client that, in turn, maximizes the expected value of the project. Their model is designed to study licensing between the research unit and a company (the "client"). It is less suitable for describing contracting for spin-off formation, particularly within universities, where beyond the researcher, whose efforts need to be encouraged and the "client" and/or VC whose investment is required, there is the TTO that owns but will not use the invention. Also, Demougin and Fabel (2007) study the optimal sharing of the project's expected surplus in an environment where consulting firms play the role of intermediaries, matching ideas (researchers) and liquidity constrained professionals.

Very few theoretical models on technology transfer focus on academic spin-offs. Chukumba and Jensen (2005) develop a model of university licensing, considering the spin-off option in case the TTO is unable to find an established firm willing to purchase the license for the technology. The TTO may assist the inventor in searching for a venture capitalist to fund the start-up but typically will focus its efforts on licensing to established firms. The Chukumba \& Jensen model predicts that start-ups only occur when they earn greater expected profits as compared to an established firm, that is, when the start-up firm has an advantage in development or commercialization. Their model focuses on the choice between licensing and spin-offs, abstracting from moral hazard problems.

A final issue of relevance for understanding technology transfer activities of universities is the trade-off between applied and basic research and the quality of teaching when the faculty is engaged in technology transfer (Jensen and Thursby, 2001). In accordance with an institutional approach to the analysis of science (e.g., Dasgupta and David, 1994), academics are taken to have specific objectives they pursue, and incentive systems they respond to. More particularly, academics derive direct benefit from fundamental research in the form of 
publications and peer recognition. Just like industrial actors, academics involved in technology transfer will respond to economic incentives but, in addition, they will also value the peer recognition from research and own commercial activities, which may be positive or negative. Lacetera (2005) discusses the decision by academic research teams of whether and when to undertake commercially oriented activities and their performance, as compared to those of industrial teams, taking into account the differences in objectives and organizational structures. He shows that academic scientists tend to select less, and hence on average more profitable projects to commercialize than industrial scientists. In addition, Aghion et al. (2005) model the specific characteristics of agents belonging to the scientific community as compared to industrial teams when discussing the decision whether to commercialize. These models are helpful in explaining the differential performance of academic versus nonacademic spin-offs and the decision when to license versus spinning off.

In this paper, we provide a theoretical model for how a university technology transfer office should design its spin-off contracts, taking into account the moral hazard problem of key researcher involvement in the spin-off, the participation constraints of the researcher and the venture capitalist, and the asymmetric information problem related to the success of the venture.

Our model has been designed to incorporate the specifics of university spin-off contracts. A first specific characteristic is the key role of the university technology transfer office. Its role is modeled on what is by now the most common practice in the EU (cf. Debackere and Veugelers, 2005); it operates as an autonomous unit within the university that deals with technology transfer; it owns the intellectual property of university research results and therefore sets the terms of the contracts. Its main objective function is to maximize for the university the revenues from technology transfers (see also Thursby et al., 2001). But we also discuss the implications of having the TTO take a longer-term perspective that takes into account academic research concerns. As an autonomous unit of the university and an intermediary between research and the market, the TTO can develop a capacity to assess the commercial value of university inventions that is better than that of the researcher and/or the venture capitalist. ${ }^{3}$ A second specific characteristic of the model is the trade-off in the key researcher's objective function between dedicating effort to advising the spin-off and academic research concerns. We

3. In some sense, the TTO plays the role of assembling resources, as the entrepreneurs in Hellmann (2007). 
comment on the extent to which our results can be generalized beyond a university spin-off setting in the concluding section.

Our model builds strongly on empirical evidence from the KULeuven experience. The following box details the organizational features of the KULeuven technology transfer and spin-off process that motivates our model set-up.

\section{Managing Spin-off Activities within Universities: The Case of KULeuven LRD ${ }^{4}$}

KULeuven Research \& Development (LRD) was founded in 1972 to manage the industry component of the R\&D portfolio of the Catholic University of Leuven, Belgium. It currently represents about onequarter of the total university research budget and employs 34 support staff professionals, giving it the critical size, expertise, and experience required for success in technology transfer, as evidenced in most empirical studies, cf. supra.

From its start, LRD has received a large amount of budgetary and human resource management autonomy within the university. LRD, although being fully integrated within the university, manages its own budgets as well as the research personnel financed by these budgets. Researchers belonging to different departments and faculties can decide to integrate the commercial-industrial component of their knowledge portfolio in a research division at LRD. A group of "officers" act as liaison between LRD and its major divisions and scientific areas, helping to spot and develop ideas fit for commercialization. In fact, most LRD officers and managers have a mix of science and management background that often allows them to better assess the market potential of scientific projects than the inventor or the venture capitalists.

The creation of spin-off companies constitutes a third pole of activity, in addition to those of contract research and patenting/licensing. In 2004, the university had generated 61 spin-off companies. These spinoffs generated a turnover of 350 million Euros and employed over 2000 people. Two spin-offs have realized a successful IPO on NASDAQ and EASDAQ. There have been eight failures. However, the highest failure rate occurs during the phase of spin-off creation. About two-thirds of the projects never make it to the actual stage of spin-off incorporation.

LRD's venture unit has developed the necessary mechanisms and processes that assist in business development. A major focus of LRD is first to assist the academic entrepreneurs in developing their business plans. Finding a proper funding structure, as well as the right management team, figures high on the agenda of the LRD venture unit.

4. See Debackere and Veugelers (2005) for a more in-depth analysis of LRD. 
The university, in partnership with two major Belgian banks, created two seed capital funds to fund start-up companies that exploit universitybased know-how. LRD together with two investment managers from both banking partners constitute the investment committee. Accommodation for its spin-offs is provided through an "Innovation \& Incubation Center." In addition two science parks are available in the close vicinity of KULeuven.

But perhaps the most significant factor explaining LRD's success is its incentive system. Whereas the incentive system within the departments and faculties of the university uses promotion up the academic ladder, LRD has developed an incentive system that is based on budgetary flexibility and financial autonomy. LRD research divisions enjoy complete autonomy to balance revenue and expenses from their ISL activities. LRD divisions are further entitled to participate both intellectually and financially in the spin-off companies that they have started and developed. Finally, incentives are given to individual researchers as well. In the case of spin-off creation, individual researchers can receive intellectual property shares (i.e., the intellectual property stock or founder shares) in exchange for the input of their know-how and goodwill. They can also invest financially in the spin-off and hence obtain a pro rata share in the common stock (capital shares) of the company. In the case of lump sum and royalty payments proceeding from license agreements, individual researchers are entitled to receive in a step system up to $30 \%$ of the income generated (after expenses have been recouped), typically with a nonlinear royalty rate.

Academics as top generators of new technology ventures and industrial contract volumes also tend to be among the top performers in terms of academic research and patents, further supporting the importance of a broad variety of complementary activities in the activity profile of a technology transfer unit (Van Looy et al., 2006).

\section{THE MODEL}

The empirical literature has indicated that universities that are successful in spin-off creation pay due attention to incentive schemes and allocation of shares in spin-off contracts. Our model studies the optimal allocation of these shares. Three agents are involved: the university, represented by its independent technology transfer unit (TTO), which owns the innovation and sets the contracts; the researcher (or the research team), whose effort is needed for the development of the innovation; and the venture capitalist (the VC hereafter), who provides financial capital. The university TTO and the researcher can also provide financial capital 
to the project, but they have a higher opportunity cost for the capital than the VC. ${ }^{5}$ The spin-off success and its value depend on the involvement of the researcher who has developed the initial innovation and on the financial capital invested in it. This researcher's involvement does not include management of the spin-off, for which dedicated personnel is hired within the spin-off, but includes technological consulting. The researcher typically remains employed within the university.

More precisely, the expected value of the spin-off is $p B(e, F)$, where $p$ denotes the probability of success. The function $B(e, F)$ represents the profits of the venture in the case of success, which depend crucially on researcher's effort $e$ and on financial capital invested $F .{ }^{6}$ For the sake of simplicity, we assume that there are only two possible efforts: $e \in\left\{e^{L}\right.$, $\left.e^{H}\right\}$, with $e^{L}<e^{H}$. We also assume $B\left(e^{H}, F\right)>B\left(e^{L}, F\right)$ for all $F>0$ and that $B(e, F)$ is strictly increasing and strictly concave in $F$.

We consider an initial innovation for which the decision to develop this further through a spin-off rather than through licensing has already been made (cf. Chukumba and Jensen, 2005). The licensing alternative only shows up in the reservation utilities of the players. ${ }^{7}$ The timing of the game is the following. First, the university TTO designs and offers the contracts to the researcher and the $\mathrm{VC}^{8}$ Second, these two agents accept or reject their contracts. ${ }^{9}$ If both the researcher and the VC accept the contracts then the capital is invested and the researcher provides the effort. Finally, nature decides the result, which is assumed to be observable.

The contract specifies the financial contributions and the (contingent) payments. We assume that the researcher's effort is not verifiable; hence it cannot be part of the contract. Concerning the financial contribution, the contract states the total capital invested, $F$, and the

5. The financial capital provided by the researcher (or research team) is not necessarily her (their) own personal wealth, but typically involves reserves from research funds acquired by the research unit (cf. LRD case).

6. The model could also be interpreted as researcher's efforts influencing the expected value of the spin-off through the probability of success $p$, rather than only the benefits $B$.

7. The licensing game is also an interesting game whose outcome depends on the value of the innovation and on the effort that the researcher makes to transfer the technology to the firm (see Macho-Stadler et al., 1996 and Jensen and Thursby, 2001). By "playing" this game, the TTO and the researcher (as well as the licensee) obtain a certain payoff, which can be considered as their reservation utilities. In this paper, as already discussed, we assume that spinning-off is a superior alternative to licensing for the technology at hand.

8. The researcher cannot run the spin-off by herself. We assume that the TTO has the intellectual property rights on the innovations obtained at the university, as is by now the common practice in most OECD countries.

9. The acceptance decision is sequential in order to avoid equilibria where (even when the contracts are acceptable for the researcher and the VC) each agent rejects the contract because the other also does. 
TABLE I.

TERMS OF THE CONTRACT SHARES

\begin{tabular}{lclllc}
\hline Agent & Total Shares & & Financial Shares & & Founder Shares \\
\hline University TTO & $s^{T}$ & $=$ & $f^{T}$ & + & $i^{T}$ \\
Researcher & $s^{R}$ & $=$ & $f^{R}$ & + & $i^{R}$ \\
Venture Capitalist & $s^{V}$ & $=$ & $f^{V}$ & & $i^{V}=0$ \\
\hline
\end{tabular}

contribution of each participant: $F^{T}, F^{R}$, and $F^{V}$, with $F^{T}+F^{R}+F^{V}=$ $F$. As to the payments, we assume that payoffs can only be based on the final outcome. The contract sets the shares that each agent gets of this outcome. We will distinguish two types of shares: financial shares and founder (intellectual property) shares (cf. LRD case). The first type of shares is directly related to the capital invested. The second type, founder shares, reflect the compensation for the intellectual property brought in by the researcher and her team and owned by the university TTO. Table 1 summarizes the terms of the contract shares.

Obviously, $s^{T}+s^{R}+s^{V}=1$, and all shares take values in the interval $[0,1]$. Financial shares must be proportional to the capital invested, that is,

$$
\frac{F^{i}}{F^{j}}=\frac{f^{i}}{f^{j}}, \quad \text { for all } i, j=T, R, V .
$$

We typically have $i^{V}=0$, because the VC does not contribute intellectual property.

We now define the objective function of the three agents. The venture capitalist incurs a cost from investing capital that reflects his outside market opportunity. We denote by $r^{V}$ the unit cost of capital of the VC. Hence, his expected profits when he invests the amount $F^{V}$ and receives the shares $s^{V}$ are equal to

$\pi^{V}=s^{V} p B(e, F)-r^{V} F^{V}$.

We assume, without loss of generality, that the VC's reservation utility is equal to zero.

The researcher's utility function is

$U^{R}=s^{R} p B(e, F)-c(e)-r^{R} F^{R}$,

where $c(e)=C(e)+\lambda(e)$.

The function $c(e)$ represents the cost of making the effort $e$. In this type of project, this cost usually has two different components. $C(e)$ represents the usual cost associated to devoting time and effort to the spin-off, including the opportunity cost of lost time for other 
activities, as for instance academic research. The specific nature of the agent providing the effort for the spin-off, being an academic, leads to including a second term in the cost function $c(e)$. Researchers are driven by monetary rewards, like any other nonacademic entrepreneur, but in addition they may, in contrast to other entrepreneurs, also be concerned by peer recognition and the "puzzle" joy from research (cf. Stephan and Levin, 1992). The term $\lambda(e)$ represents the nonmonetary utility that the researcher pays by being involved in the spin-off. It can be positive if there are negative spillovers to basic research and/or the researcher loses peer recognition from spin-off involvement (see also Lacetera, 2005). Alternatively, $\lambda(e)$ can also be negative, if involvement in spin-off activities give positive spillovers to basic research in terms of increased research insights, increasing funding for academic research, or gaining peer recognition. We denote $r^{R}$ the unit cost of capital for the researcher and $\underline{U}^{R}$ her reservation utility. This reservation utility summarizes the gains from alternative options. It could reflect the returns from academic research or the returns she would get in case the invention is transferred via a license rather than a spin-off. We assume that the cost of providing financial funds for the researcher is higher than for the VC: $r^{R}>r^{V}$.

Finally, we assume that the TTO's objective function is the net revenue from the spin-off:

$U^{T}=s^{T} p B(e, F)-r^{T} F^{T}$,

where $r^{T}$ is the unit opportunity cost of the capital invested by the university, $r^{T}>r^{V}$. $^{10}$ This objective function is consistent with survey evidence suggesting the predominance of revenue maximization among TTOs (see, for instance, Thursby et al., 2001, and Markman et al., 2005). In addition, the evidence from the LRD case supports the importance of the commercial value of the spin-offs being generated rather than the number of spin-offs. ${ }^{11}$ For simplicity, we do not take into account alternative payoffs for the TTO, although the possibility of licensing the invention could be considered as its reservation payoff (see also footnote 7).

We assume that for the project to be profitable it is necessary for the researcher to exert high effort. Because effort is not verifiable, the contract should satisfy the researcher's incentive compatibility constraint

10. As Markman et al. (2005) state, TTOs are extremely risk averse with respect to financial risks and therefore will face a higher cost of capital for spin-off financing than venture capitalists, who can diversify these risks on financial markets.

11. The TTO being an independent entity does not need to internalize other university concerns, like teaching or scientific prestige. This does not exclude that these other objectives can be part of the TTO's mission. We will discuss some extension of the TTO's objective function at the end of Section 4 . 
(ICC) that can be written as

$s^{R} p B^{H}(F)-c^{H} \geq s^{R} p B^{L}(F)-c^{L}$,

where we denote $B^{H}(F) \equiv B\left(e^{H}, F\right), c^{H} \equiv c\left(e^{H}\right)$. Denoting $\Delta c \equiv c^{H}-c^{L}$ and $\Delta B(F) \equiv B^{H}(F)-B^{L}(F)$, we can write the ICC as

$s^{R} \geq s^{R^{\circ}} \equiv \frac{\Delta c}{p \Delta B(F)}$.

The minimum share that provides incentives to the researcher, $s^{R^{\circ}}$, is lower the higher the probability of success of the venture is, the more profitable the project is in case of high effort, and the less costly exerting high effort is.

\section{The Optimal Sharing Contract}

The university TTO, having the property rights over the critical IP, decides on the contract $\left\{\left(s^{T}, F^{T}\right),\left(s^{R}, F^{R}\right),\left(s^{V}, F^{V}\right)\right\}$ to maximize its expected utility, taking into account the researcher's ICC and both participation constraints (PCs). That is, the optimal contract is the solution to the following program:

$\operatorname{Max}_{\left\{\left(s^{T}, F^{T}\right),\left(s^{R}, F^{R}\right),\left(s^{V}, F^{V}\right), F\right\}}\left\{s^{T} p B^{H}(F)-r^{T} F^{T}\right\}$

s.t. $\quad s^{R} \geq \frac{\Delta c}{p \Delta B(F)}$

$s^{R} p B^{H}(F)-c^{H}-r^{R} F^{R} \geq \underline{U}^{R}$

$s^{V} p B^{H}(F)-r^{V} F^{V} \geq 0$

$s^{T}+s^{R}+s^{V}=1$

$F^{T}+F^{R}+F^{V}=F$

$F^{T} \geq 0, F^{R} \geq 0, F^{V} \geq 0$

where (1) is the researcher's ICC, (2) is the researcher's PC, (3) is the VC's PC, (4) states that the benefits from the spin-off are shared among the three agents, (5) states the sharing of the capital, and (6), (7), and (8) are the nonnegativity constraints of the financial contributions.

Apart from the constraints that appear in the program, some others have to hold. The constraint $s^{R} \geq 0$ always holds given (1) and $s^{V} \geq$ 
0 is satisfied because of (3). The constraint $s^{T} \geq 0$ holds if the spinoff is profitable in expected terms. We will write the optimal contract assuming that the spin-off is profitable in the case of high effort (this is always the case if $p$ is high enough). A necessary condition is $p B^{H}(F) \geq$ $c^{H}+\underline{U}^{R}+r^{V} F$ for some $F$.

To better highlight the characteristics of the optimal contract, we first consider spin-offs where the level of total investment $F$ is given, that is, spin-offs whose required level of financial capital is exogenously determined by technical and market conditions. The TTO only decides about the sharing of $F$. In Section 5, we characterize the optimal level of $F$ when the investment is endogenous.

Proposition 1 portrays the optimal sharing contracts when $F$ is fixed. We simplify notation and use $B^{H}$ and $\Delta B$ instead of $B^{H}(F)$ and $\Delta B(F)$. We differentiate among three regions of parameters:

Region I: $\frac{\Delta c}{\Delta B} \leq \frac{c^{H}+\underline{u}^{R}}{B^{H}}$,

Region II: $\frac{\Delta c}{\Delta B} \in\left(\frac{c^{H}+\underline{u}^{R}}{B^{H}}, \frac{c^{H}+\underline{u}^{R}+r^{R} F}{B^{H}}\right)$ and,

Region III: $\frac{\Delta c}{\Delta B} \geq \frac{c^{H}+\underline{\underline{u}}^{R}+r^{R} F}{B^{H}}$.

Proposition 1: For a given $F>0$, the optimal contract is $F^{T}=0, F^{V}=F-F^{R}, s^{T}=1-s^{R}-\frac{r^{V}\left(F-F^{R}\right)}{p B^{H}}, s^{V}=\frac{r^{V}\left(F-F^{R}\right)}{p B^{H}}$, and $\left(F^{R}, s^{R}\right)$ given by

(Region I): $\quad F^{R}=0$ and $s^{R}=\frac{c^{H}+\underline{u}^{R}}{p B^{H}} ;$

(Region II): $\quad F^{R}=\frac{B^{H}}{r^{R}}\left[\frac{\Delta c}{\Delta B}\right]-\frac{c^{H}+\underline{u}^{R}}{r^{R}} \quad$ and $\quad s^{R}=\frac{\Delta c}{p \Delta B} ;$

(Region III): $\quad F^{R}=F \quad$ and $\quad s^{R}=\frac{\Delta c}{p \Delta B}$.

Hence, for a given $F$, the researcher's contract has the form shown in Figure 1.

The left region in Figure 1 (Region $I$ ) depicts the situations where it is easy to give the researcher incentives to provide effort: with the ratio $\Delta c / \Delta B$ being small, supplying high effort is not very costly and/or it is 


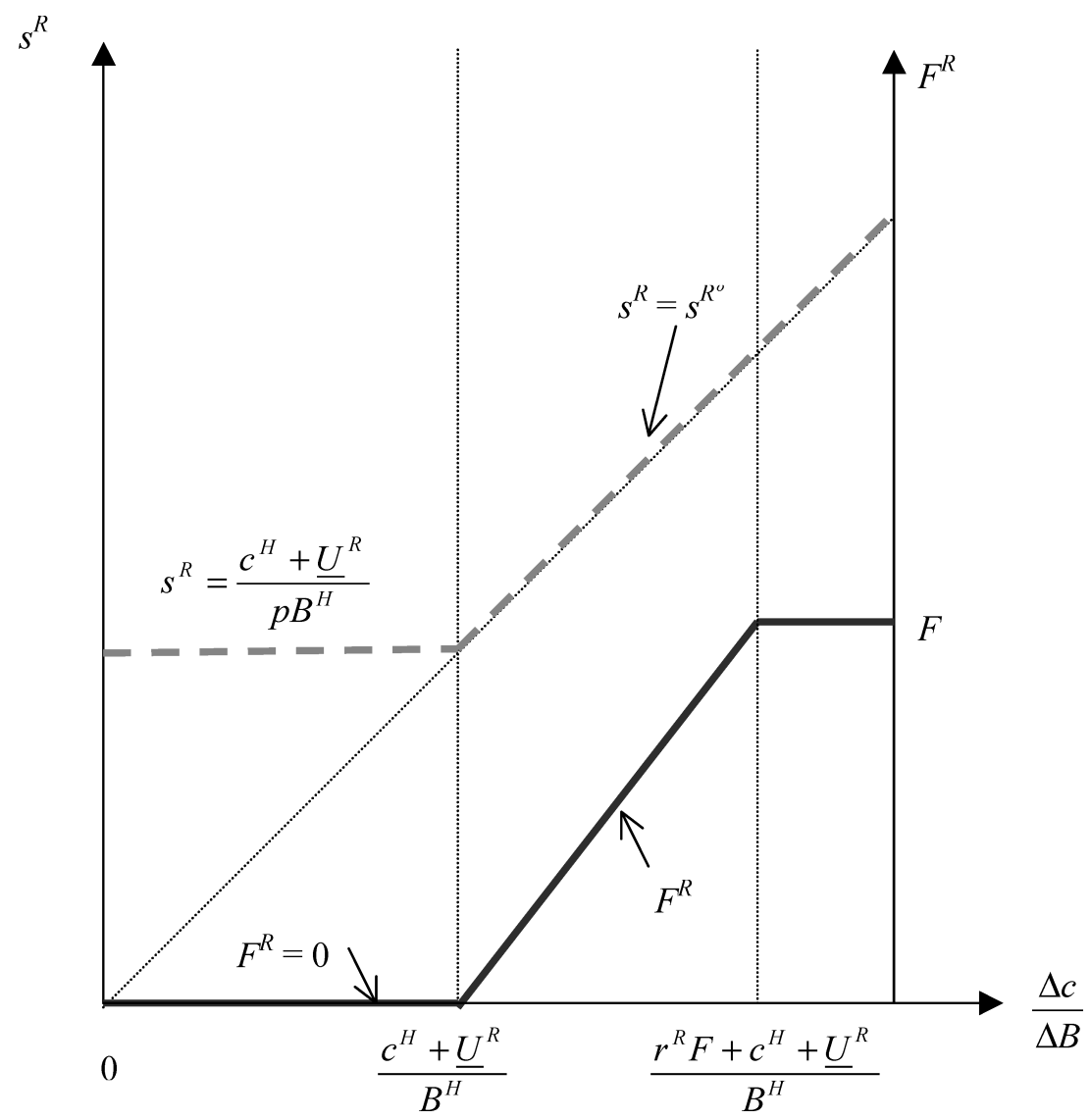

FIGURE 1.

OPTIMAL SHARES FOR A GIVEN F >0

very profitable. In this region, the number of (founding) shares given to the researcher for her to participate in the venture provides more than enough incentives for her to work hard. Hence, in this region, the PC is binding while the ICC is not. ${ }^{12}$ Given $r^{R}>r^{V}$ and $r^{T}>r^{V}$, it is better that the VC provides the financing, so $F^{T}=F^{R}=0$. Note that efficiency arguments explain that the university's financial involvement is zero in all regions (the TTO does not need to be induced to provide effort).

More interesting results arise when the moral hazard problem is more severe, which corresponds to Region II. In this case, the researcher

12. Note that in Region I (and only in this region) the TTO could offer the researcher an equivalent optimal contract involving a smaller number of shares (but still satisfying $\left.s^{R} \geq s^{R}\right)$ and a fixed transfer as long as the expected payment is equal to $\underline{U}^{R}$. 
needs more inducement to provide effort, so the contract must give her more shares. Given this situation, the TTO will require the researcher to participate in the financing of the venture up to an amount so that her PC is binding; hence the researcher will be required to put money on the table, taking financial shares: $F^{R}$ is positive. The amount of the researcher's financing depends on the severity of the moral hazard problem, that is, $F^{R}$ is increasing with $\Delta c / \Delta B$. Even if this financial arrangement is not efficient (because the opportunity cost of the capital for the researcher is higher than $r^{V}$ ), it allows the TTO to obtain larger profits because it induces higher effort by the researcher. In this region, both the PC and the ICC of the researcher are binding.

Finally, it can even be the case that the total financing $F$ needed in the project is lower than the amount of money the researcher would contribute. In this case, which corresponds to Region III and is represented in the right side of Figure 1, the researcher finances the project completely and her ICC is binding while her PC is not. In this region, there will be no venture capital.

Proposition 2 translates the main characteristics of the optimal contract into the agreement on financial and founding shares (the items in Table I) that will be settled between the TTO, the researcher, and the VC:

PROPOSITION 2: For a given $F>0$, the optimal sharing contract is the following:

(Region I): $\quad f^{T}=f^{R}=0, f^{V}=\frac{r^{V} F}{p B^{H}} ; \quad i^{T}=1-\frac{c^{H}+\underline{u}^{R}+r^{V} F}{p B^{H}}$; and

$$
i^{R}=\frac{c^{H}+\underline{u}^{R}}{p B^{H}} .
$$

(Region II): $f^{T}=0, f^{R}=\frac{r^{V}}{r^{R}} \frac{\left(B^{H}\left[\frac{\Delta c}{\Delta B}\right]-c^{H}-\underline{U}^{R}\right)}{p B^{H}}$,

$$
\begin{aligned}
f^{V} & =\frac{r^{V} F}{p B^{H}}-f^{R} ; \quad i^{T}=1-i^{R}-\frac{r^{V} F}{p B^{H}} ; \quad \text { and } \\
i^{R} & =\frac{\left(r^{R}-r^{V}\right) B^{H}\left[\frac{\Delta c}{\Delta B}\right]+r^{V}\left(c^{H}+\underline{U}^{R}\right)}{r^{R} p B^{H}},
\end{aligned}
$$

(Region III): $\quad f^{R}+i^{R}=\frac{\Delta c}{p \Delta B}, f^{T}=f^{V}=0, \quad$ and $\quad i^{T}=1-\frac{\Delta c}{p \Delta B}$.

The terms of the optimal sharing contract are depicted in Figure 2. 


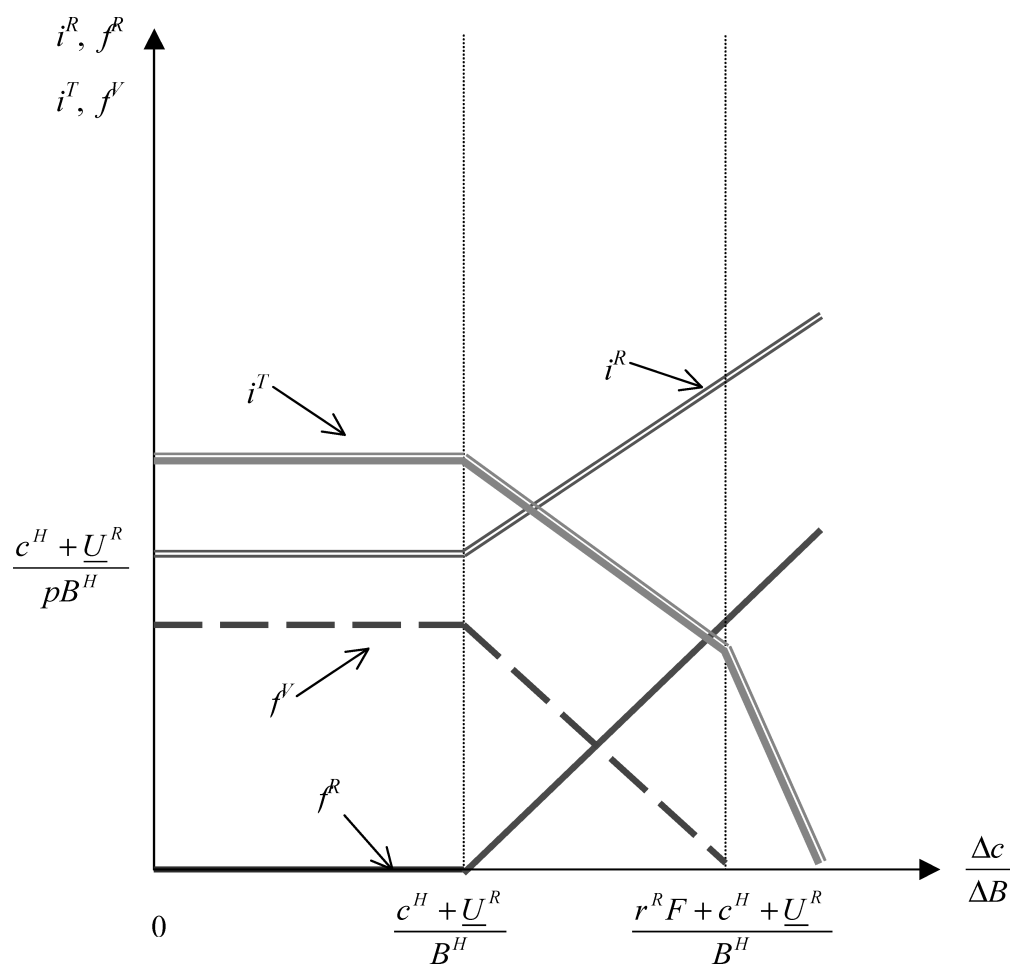

FIGURE 2.

OPTIMAL CONTRACT FOR A GIVEN F > 0

In Region $I$, having not made any financial investment $\left(F^{R}=0\right)$, the researcher receives only founder shares $i^{R}$. The VC receives all the financial shares to compensate, at the market value, his contribution $F^{V}=F$; hence, $f^{V}=r^{V} F / p B^{H}$. Once having compensated the researcher and the VC for their participation, the university TTO appropriates its founder shares $i^{T}=1-i^{R}-f^{V}$. The VC also receives a "fair" ("marketvalued") number of shares to compensate his financial involvement when the spin-off is in Region II. This value also determines the amount of financial shares that should accrue to the researcher given her financial participation in the project. The rest of her shares are given as intellectual founder shares, to make her PC binding. The residual founder's shares are kept by the TTO. Finally, no venture capital is involved in the spinoff in Region III. The researcher is given all the shares needed to provide incentives for her to work hard (whether the shares are given as financial or founder shares does not matter), and the TTO keeps the rest as founder shares. 
Figure 2 has shown the variation of the optimal sharing contract as a function of $\Delta c$ and $\Delta B$, the parameters reflecting the severity of the moral hazard problem The next corollary presents the comparative static of the shares that the participants receive as a function of the exogenous parameters $\underline{U}^{R}, r^{V}, r^{R}$, and $p$ in Regions $I$ and $I I$ (similar effects appear in Region III, with any "reasonable" decomposition of $s^{R}$ in $f^{R}$ and $i^{R}$ ).

COROLLARY 1: For a given $F>0$, the optimal sharing contract has the following properties:

- Shares $f^{R}$ and $i^{T}$ are nonincreasing while $i^{R}$ and $f^{V}$ are nondecreasing with $\underline{U}^{R}$ and $r^{R}$.

- Shares $f^{R}$ and $i^{T}$ are nondecreasing while $i^{R}$ and $f^{V}$ are nonincreasing with $\lambda(e)$.

- Shares $i^{R}$ and $i^{T}$ are nonincreasing while $f^{R}$ and $f^{V}$ are nondecreasing with $r^{V}$.

- Shares $f^{R}, i^{R}$ and $f^{V}$ are nonincreasing while $i^{T}$ is increasing with $p$.

A higher researcher's reservation utility (or an increase in the value of the nonmonetary cost $\lambda(e)$ by being involved in the spin-off, which would increase $c(e)$ ), will result in a contract that includes more founder shares and fewer financial shares for the researcher. Hence, we should expect to see a higher rate of founder shares for researchers who are more reluctant to participate in spin-offs, as may be the case for researchers whose inventions would have a higher alternative return through licensing. A similar result holds with respect to a higher cost of capital for the researcher. Hence, we should expect higher financial shares and lower founder shares associated with research teams with higher income coming from research contracts.

With respect to the profitability of the venture, as measured by $p$, more (ex ante) profitable spin-offs lead to fewer shares for the researcher and the $\mathrm{VC}$, which will lead to a larger portion of founder shares accruing to the university TTO. Hence the TTO clearly has an incentive to invest in selecting projects with a high $p$ and/or improving the venture's probability of success, not only because they give higher profits to the TTO directly but also indirectly because the TTO can secure a higher share of the higher profits, needing to leave less on the table to induce participation and provide incentives.

For a given research quality, researchers that are more oriented toward applied research would have a smaller reservation utility to participate in the spin-off, and a lower cost of providing effort for technical consulting for the spin-off. All this will result in these researchers' having less founder shares than more basic researchers. The difference in the number of founder shares will be even larger if, as it is often thought, 
basic researchers lose (more) peer recognition from the spin-off activity (i.e., the part $\lambda(e)$ of the cost function is high).

As for star researchers, engaged in basic or applied research, we would expect them to have a higher reservation utility $\underline{U}^{R}$ calling for higher founder shares to compensate for their opportunity cost from not being able to do research. As for the size of the moral hazard problem, the effect of stardom is ambiguous. On the one hand, the higher ability of star researchers can translate in lower cost for effort (e.g., in terms of time to reach results). On the other hand, they may care more about the possible negative effect on peer recognition.

In all the cases where the participation and/or incentive constraints of the researchers are more severe, spin-off projects will only be selected if their expected return is sufficiently high. This would predict a positive correlation between the spin-off expected return and, for instance, the basicness of the researcher. These results are interesting for empirical analysis on the determinants of the performance of university spin-offs where self-selection issues are likely to be present. ${ }^{13}$

Finally, we check the robustness of our results to how we have modeled the utility function of the TTO. In some cases, one may argue that the University TTO not only cares about the revenues it obtains from spin-offs but also takes into account more broader academic concerns. Because its long-run viability depends on the size and quality of research it can build on, the TTO should also care about what drives the utility of the faculty that produces this research. This could be reflected in the following utility function specification: $U^{T}=s^{T} p B(e, F)-r^{T} F^{T}+k U^{R}$. The parameter $k$ would reflect the intrinsic concern of the TTO for the researcher's utility. In Macho-Stadler et al. (2006), we check that all the results in the paper hold without any modification as long as $k$ is sufficiently small $\left(k \leq r^{V} / r^{R}\right)$. When the university TTO is very concerned about the well-being of its researchers $\left(k>r^{V} / r^{R}\right)$, it prefers to increase the researcher's utility rather than introduce an inefficiency in the relationship by forcing her to take a financial stake in the venture. Hence, in the optimal contract, $F^{R}=0$ always.

\section{OPTIMAL INVESTMENT}

In this section, we analyze the optimal choice by the TTO of the financial funds F. Part of the activities of the TTO's venture unit is indeed to determine the amount of financial investments needed for take-off (cf.

13. Similarly, Lacetera (2005), comparing industrial and academic spin-offs, finds that academic scientists tend to enter commercial projects with higher returns than commercial actors because scientists are more reluctant to commercialize research. 
LRD case). This includes considering technical and market parameters together with the researcher's moral hazard problem. For the sake of simplicity, we will assume that $B^{H}(F)=b^{H} g(F)$ and $B^{L}(F)=b^{L} g(F)$, with $g^{\prime}(F)>0$ and $g^{\prime \prime}(F)<0$, for all $F \geq 0$.

\section{Proposition 3: The optimal investment level is}

(1) $F=F^{\circ}$, where $F^{\circ}$ is defined by $p b^{H} g^{\prime}\left(F^{\circ}\right)=r^{V}$, if $\frac{\Delta c}{\Delta b} \leq \frac{c^{H}+\underline{u}^{R}+r^{R} F^{o}}{b^{H}}$;

(2) $F=\frac{b^{H}}{r^{R}}\left[\frac{\Delta c}{\Delta b}\right]-\frac{c^{H}+\underline{U}^{R}}{r^{R}}$, if $\frac{\Delta c}{\Delta b}>\frac{c^{H}+\underline{U}^{R} r^{R} F^{o}}{b^{H}}$;

The optimal decision shown in Proposition 3 is depicted in Figure 3 (where we also plot $F^{R}$ ). The capital invested is increasing in the ratio $\Delta c / \Delta b$, which as before is a measure of the researcher's moral hazard problem.

The main intuition of Proposition 3 is the following. When the moral hazard problem is not very important, the founder shares allocated to the researcher for her to participate in the spin-off give her enough incentives to work hard (this corresponds to Region $I$ in Proposition 1). All the financing is provided by the $\mathrm{VC}$ at a unit cost of the capital $r^{V}$. The optimal investment level $F^{\circ}$ is efficient, reflecting the equality between marginal benefits and marginal cost. The optimal investment is still $F^{\circ}$ even if the researcher finances part of the capital, as long as the required involvement to solve the moral hazard problem is lower than this level (Region II). The previous analysis corresponds to part (1) in Proposition 3.

When the moral hazard problem is very severe (and/or the researcher's reservation utility is very low), the number of financial shares that must be allocated to the researcher is very large, eventually corresponding to an investment larger than $F^{\circ}$. Given that, the TTO has incentives to increase total investment accordingly as described in part (2) of Proposition 3. Although the unit cost of capital in this case is $r^{R}$, from the point of view of the TTO, the cost is zero.

Therefore, the need to provide incentives to the researchers in spin-offs to solve the moral hazard problem can lead to two separate inefficiency problems. First, an inefficiency is introduced any time the researcher is financially involved in the venture (the two regions on the right in Figure 3) because her cost of capital is larger than that of the VC. Second, when the investment cost is endogenous, in addition to the first problem, "overinvestment" in spin-offs appears in the cases where all the financing is made by the researcher (the regions on the right in Figure 3). 


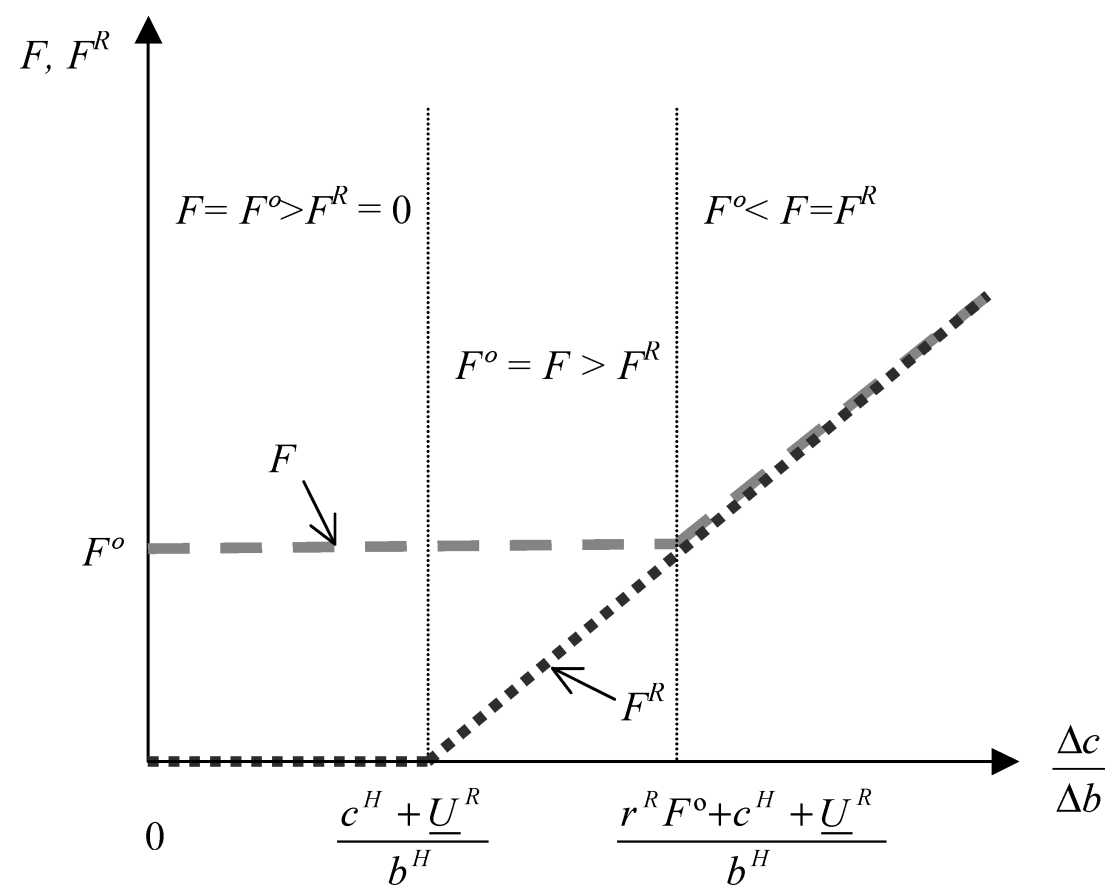

FIGURE 3.

OPTIMAL INVESTMENT F

\section{The informational Advantage of the tTO}

In the previous sections, we have analyzed the optimal sharing contracts among the TTO, the researcher, and the VC assuming that the only major informational problem in the venture is that the researcher needs incentives to provide effort. In this section, we address the design of the spin-off contracts when information about the profitability of the project is not symmetric.

Of the three participants in the project, the one with information about both the scientific and the commercial value of the venture is the TTO. A good technology transfer office has boundary-spanning personnel, which combine technical with commercial expertise. These boundary-spanning people know about the scientific content of the innovation. They are in close contact with the researchers and with the "outside world," which helps in assessing and even shaping the potential commercial value of the invention. In addition, by experience, they have better knowledge than the other two participants (especially the researcher) about the commercialization of inventions and the 
steps and difficulties that the spin-off will encounter on its path to commercialization. Therefore, a good TTO can be assumed to have better information than the researcher and the VC concerning the potential value of the spin-off.

To model this asymmetric information situation in a simple way, we assume that the probability of success of the venture can be either $p_{1}$ or $p_{2}$, with $p_{1}>p_{2}$. The TTO knows the true value of the probability of success, but the researcher and the VC do not. In addition, for simplicity we consider a situation where the moral hazard problem is not very acute (i.e., the parameters lie in Region $I$ in Proposition 1). ${ }^{14}$ Finally, we suppose that the spin-off is only profitable when the probability of success is high, that is, $p_{1} B^{H}>\underline{U}^{R}+c^{H}+r^{V} F$ and $p_{2} B^{H}<\underline{U}^{R}+c^{H}+$ $r^{V} F \cdot{ }^{15}$

Under symmetric information, when the TTO faces a good project, it offers a contract involving $s_{1}^{T *}=i_{1}^{T}=1-\frac{c^{H}+\underline{U}^{R}+r^{V} F}{\bar{p}_{1} B^{H}}>0$ and $F_{1}^{T *}=0$. But, when the TTO has private information concerning the quality of the project, the previous contract is even more profitable for the TTO if the chances of success are small. Therefore, if the probability of success is unknown to them, the researcher and the VC will never accept such a proposal by the TTO. To be acceptable, the contract must be a clear "signal" that the project is indeed a good one.

For a contract to signal that the project of the TTO is good it has to be the case that it would never be offered when the project is a bad one. That is, the contract must satisfy the following ICC for the TTO:

$s^{T} p_{2} B^{H}-r^{T} F^{T} \leq 0$.

There are many contracts that satisfy the previous condition. Several criteria have been proposed in the literature to refine the set of equilibria. The most widely used criterion to eliminate some "unreasonable" Bayesian equilibria is the "intuitive criterion," proposed by Cho and Kreps (1987). The next proposition characterizes the unique contract that satisfies this criterion.

Proposition 4: For a given $F>0$, if the parameters lie in Region I, when the TTO has private information concerning the probability of success, the unique contract designed for good projects that satisfies the intuitive criterion

14. We present this case for the sake of simplicity of exposition, to avoid the exhaustive presentation of the results for many parameter combinations when all of them lead to similar results.

15. Generalizations of the proposed model will not alter the qualitative results. In particular, the analysis and the results are similar if the environment is such that both projects are profitable under symmetric information, that is, if $p_{2} B^{H}>\underline{U}^{R}+c^{H}+r^{V} F$. 
is $\quad F^{R}=0, F^{V}=F-F^{T}, \quad s^{T}=1-s^{R}-\frac{r^{V}\left(F-F^{U}\right)}{p_{1} B^{H}}, s^{V}=\frac{r^{V}\left(F-F^{T}\right)}{p_{1} B^{H}}$, and $\left(F^{T}, s^{R}\right)$ given by

(i) $F^{T}=\frac{p_{2}\left(p_{1} B^{H}-U^{R}-c^{H}-r^{V} F\right)}{p_{1} r^{T}-p_{2} r^{V}}$ and $s^{R}=\frac{c^{H}+U^{R}}{p_{1} B^{H}}$,

if $p_{1} B^{H}\left[1-\frac{r^{T} F}{p_{2} B^{H}}\right]-c^{H} \leq \underline{U}^{R}$,

(ii) $F^{T}=F$ and $s^{R}=1-\frac{r^{T} F}{p_{2} B^{H}}$, if $\left[1-\frac{r^{T} F}{p_{2} B^{H}}\right] p_{1} B^{H}-c^{H} \geq \underline{U}^{R}$.

The most important characteristic of the contract highlighted in Proposition 4 is that $F^{T}>0$, that is, the TTO will provide financing. In fact, it is easy to check that this is a characteristic shared by all the contracts designed to signal good projects (not only those contracts satisfying the intuitive criterion). That is, the financial involvement of the TTO in spinoffs is a way to signal to both the researcher and the VC that the chances of success are good. It is only by getting financially involved in the project that the TTO clearly shows to its partners that it is worthwhile to provide effort (the researcher) and invest (the VC). This may explain the often observed participation of universities in the financing of spin-offs (cf. LRD case).

\section{SOME EMPIRICAL IMPLICATIONS}

Our results suggest some hypotheses that can be confronted with empirical evidence.

The number of financial shares in an optimal contract spin-off is larger (and that of founder shares smaller) for more applied research oriented researchers, for those (more embryonic) inventions that can not be licensed, and for researchers with low financial cost (e.g., for larger, well-funded research labs). Also, the number of both financial and founder shares is smaller for more (ex ante) profitable spin-offs. Concerning the TTO, our model predicts more financial shares for those offices that are more efficient (better informed) and for those spin-offs where the asymmetric information problem hampering the take-off is more acute.

We return to the KULeuven-LRD case that inspired the setup of our model, to provide some feedback on some of our model results. We screened the contracts of the spin-offs formed at LRD in the period 19972004. This involved 33 spin-offs, which is too few for robust testing and general results, but which nevertheless provides some interesting observations in support of our model results. We eliminated all incomplete cases and cases that involved consulting activities. In all these consulting cases, neither LRD nor the Venture Capital Fund (GFF) provided any funding. This would be, according to our model, consistent with the 
severity of the moral hazard problem in consulting. This left 19 cases, of which 7 were in Biomedical, 7 in ICT and 5 in Engineering.

In all these 19 cases, the researchers take a financial stake, with the exception of one spin-off. Consistent with our model results, this spinoff's know-how, business plan, and management structure was rated so highly that it succeeded in attracting as the only spin-off in the sample, international venture capital for a total amount of 3 million euro, the biggest capital investment in the sample. On average the financial shares which researchers take, $f^{R}$, is $25 \%$ (in 2 cases even more than $50 \%$ ). This could be a reflection of the substantial moral hazard problem university spin-offs have to deal with. But in addition, all of these spin-offs originate from research divisions that have already built up substantial financial reserves from previous $R \& D$ contracting that could be brought in the venture, reducing their cost of capital. Almost all of these cases (with the exception of three) were backed by venture capital funds, mostly by GFF, the KUL's own venture capital fund in joint venture with two local banks, but in some cases also outside venture capitalists. On average and excluding the zero cases, $s^{V}=f^{V}=35 \%$. This suggests that region II is the most relevant for describing the KUL-LRD reality.

In 12 of the 19 cases, the TTO office takes, in addition to its indirect stake through GFF (which it partly owns), an additional financial stake. This stake is minimal, with the average $f^{T}$ being $12 \%$, excluding the nonzero cases and excluding one outlier, where LRD took $32 \%$. This outlier spin-off was rated as a good idea, but highly risky, where according to LRD staff, it was hard to convince venture capitalists. Besides LRD, also the researchers brought in financial capital (34\%), thus being able to secure GFF funding (15\%). After its difficult start, the spin-off had two new successful capital share issues, financed by GFF. All this supports the importance of asymmetric information problems in the spin-off market, calling for financial share taking as the signaling device. LRD being a successful and well-equipped TTO is capable of taking up this signaling role.

With respect to the founder shares for the researchers, a wide dispersion is found across spin-offs, ranging from $6 \%$ to a maximum of $50 \%$, the average being $23 \% .{ }^{16}$ The three outlier cases $(43 \%, 48 \%$, and $50 \%$ ) all correspond to cases where the research team is composed of KUL star researchers, as witnessed by their research output and receiving substantial research funding from the university through a highly competitive process for rewarding basic research excellence. Although we saw in the discussion after Corollary 1 that the effect

16. We have three cases where there are no founder shares specified, neither for the researchers nor for the university, represented by LRD. 
of moral hazard on star researchers is a priori ambiguous, the LRD empirical evidence seems to suggest, as argued by the model, that an important effect is the higher opportunity cost for basic-oriented prolific researchers, calling for the TTO to leave more founder shares on the table to convince them to participate or to deal with their moral hazard problem.

Overall, the TTO's founder shares in its spin-offs, $i^{T}$ being the residual after financial shares and researcher founder shares have been set, amounts to on average $15 \%$ (excluding the three cases without founding shares). ${ }^{17}$ This not so high percentage reflects the seriousness of the incentive compatibility and participation constraints for university spinoffs, suggesting that spin-off activities for universities are not an easy and quick revenue-generating business.

Interestingly, a number of contracts stipulate the terms of the access to university research infrastructure and IP licenses and software. ${ }^{18}$ In some cases free access is granted; other cases specified fixed or variable fees. Although our model ignores these issues, this empirical evidence calls for further research to investigate how the other contract issues enter into the optimal contract design to induce participation and provide incentives.

\section{CONCLUSIONS}

Despite the policy attention devoted to academic spin-offs, the processes governing their formation and success are not yet well understood. This paper provides a theoretical analysis of how to design academic spin-off contracts. It focuses on how to allocate financial and founder (intellectual) shares in the venture to the university technology transfer office, the key researcher, and the venture capitalist. The design of the contract takes into account the moral hazard problem of the researcher's involvement in the spin-off, the participation constraints of the key researcher and the venture capitalist, and the asymmetric information problem on likelihood of success.

Our main results are the following. The optimal contract specifies the allocation to the researcher of founder shares in order to secure her involvement in the venture. But it may also require her to be financially

17. Note that the average shares reported do not sum up to $100 \%$ because the averages are calculated without the nonoverlapping zero cases.

18. As sometimes claimed, founder shares are not used for compensating the researchers and the TTO for the brought-in knowledge that can be codified through patents. If patents exist, they are always brought in the spin-off with explicit valuation in transfer and or licensing contracts. Similarly, founder shares are not used to compensate for the use of university research infrastructure, software, licenses, and so forth. 
involved in the project. Even if the unit cost of the capital provided by the venture capitalist is lower than the unit cost of the capital owned by the researcher, the allocation of financial shares to the latter may be the only way to make sure that she really has incentives to provide effort into the venture. When the moral hazard problem is acute, the need to financially involve the researcher leads to an additional inefficiency, as the optimal contract requires overinvestment in the spin-off. Finally, we show that when the TTO has more accurate information than the other two participants concerning the likelihood of success of the spin-off, the TTO will "signal" profitable projects by taking financial stakes.

Although our model has been designed specifically for discussing university spin-off contracts, the model setup is nevertheless sufficiently general that its parameters can also be read more generically to deal with other spin-off scenarios beyond academic spin-offs. Using the model to describe corporate spin-off contracts requires transforming the TTO into a commercial firm that owns the IP to the inventions, but needs to incite its key researcher/employee to provide efforts to technologically assist the venture and possibly to incite Venture Capitalists to provide financial capital. Also in corporate spin-off contracting, the principal (i.e., the parent company) may need to offer a combination of founder and financial share to solve the participation and incentive compatibility constraints of the other parties involved. Nevertheless, our model does not cover some of the key issues discussed in the corporate spin-off literature (e.g., Nerkar and Shane, 2003; Klepper and Sleeper, 2005; Cassiman and Ueda, 2006), such as the interrelatedness between the parent firm's activities and the spin-off in product markets. This will mitigate the principal's objective function with respect to spin-off performance. As compared to spin-offs, start-ups face similar participation and incentive compatibility constraints from key effort providers and venture capitalists, and can use the allocation of financial and founder shares to tackle these issues. But also in this case, the principal (i.e., the start-up company) plays a different role than a TTO. Unlike the TTO's involvement in university spin-offs, success of the start-up is also determined by the effort of the principal, who "uses" the invention (cf. Aghion and Tirole, 1994).

Although at this stage of the research, it is too early to draw robust policy conclusions, a number of interesting insights can be obtained from our analysis. First, if policy makers want more spin-offs to form with a positive expected payoff, it is important to tackle the various problems involved with spin-off formation. Our model shows that both financial and intellectual shares are important instruments to tackle moral hazard, participation constraints, and asymmetric information problems. Policy makers should avoid putting in place restrictions that would jeopardize the effective use of these instruments, such as restrictions on whether 
universities and researchers can take (financial) shares in spin-offs. Although the model clearly indicates the inefficiency of using financial shares from the researcher and the TTO rather than the venture capitalist, they are powerful instruments to solve some of the problems involved in spin-off formation. Our model results allow highlighting the trade-off between costs and benefits of using shares as contract terms.

Second, the model indicates several rationales for having a TTO. In our base model, the TTO takes no financial shares. It is the residual claimant of the relationship, simply by being the owner of the invention; hence it gets the founder shares that are left after having compensated the researcher for her participation and both the venture capitalist and the researcher for their financing. In this benchmark version, the main contribution of the TTO is related to its expertise in designing profitable spin-off contracts. Nevertheless, this base version also indicates that TTOs have an incentive to play a more active role by selecting or improving the profitability of the venture. Furthermore, if the TTO has more accurate information concerning the likelihood of the spin-off's success, TTO will "signal" profitable projects by taking financial stakes in them. All this, however, requires a TTO sufficiently endowed with financial and managerial capital.

\section{Appendix}

Proof of Proposition 1. First, note that constraint (3) holds with equality at the optimum (otherwise, the TTO could decrease $s^{V}$ and increase $s^{T}$ ). Using also equation (5) we conclude that

$s^{V}=\frac{r^{V}\left(F-F^{T}-F^{R}\right)}{p B^{H}}$.

From equations (4) and equation (9) we have

$s^{T}=1-s^{R}-\frac{r^{V}\left(F-F^{T}-F^{R}\right)}{p B^{H}}$.

Therefore, the TTO's objective function can be written as

$$
\begin{aligned}
& \left(1-s^{R}-\frac{r^{V}\left(F-F^{T}-F^{R}\right)}{p B^{H}}\right) p B^{H}-r^{T} F^{T} \\
& =\left(1-s^{R}-\frac{r^{V}\left(F-F^{R}\right)}{p B^{H}}\right) p B^{H}-\left(r^{T}-r^{V}\right) F^{T} .
\end{aligned}
$$

It easily follows that, at the optimum, $F^{T}=0$. Hence, $F^{V}=F-F^{R}$. 
Now, we can rewrite the university TTO's problem as

$\underset{\left(F^{R}, s^{R}\right)}{\operatorname{Max}}\left\{\left(1-s^{R}-\frac{r^{V}\left(F-F^{R}\right)}{p B^{H}}\right) p B^{H}\right\}$

s.t. $\quad s^{R} \geq \frac{\Delta c}{p \Delta B}$

$s^{R} p B^{H}-c^{H}-r^{R} F^{R} \geq \underline{U}^{R}$

$F^{R} \geq 0, F-F^{R} \geq 0$.

Note that, at the solution, it is necessarily the case that the Lagrange multipliers associated to the previous equations are nonnegative, that is, respectively, $\alpha \geq 0, \rho \geq 0, \mu \geq 0$, and $\theta \geq 0$. From the first-order condition with respect to $s^{R}$ and $\bar{F}^{R}$ we obtain

$\frac{\partial L}{\partial s^{R}}=-(1-\rho) p B^{H}+\alpha=0$,

$\frac{\partial L}{\partial F^{R}}=r^{V}-\rho r^{R}+\mu-\theta=0$.

From (12) and (13) we have that: $\alpha=(1-\rho) p B^{H}$ and $\rho=\left(r^{V}+\mu-\right.$ q) $/ r^{R}$.

We now distinguish three cases: $\alpha=0 ; \alpha>0$ and $\theta=0$; and $\alpha>0$ and $\theta>0$.

Region I: If $\alpha=0$, then $\rho=1$ and $\mu=-r^{V}+\theta+\rho r^{R}=r^{R}-r^{V}+$ $\theta>0$. Hence, $F^{R}=0$ from equation (7), constraint (8) holds with strict inequality and $\theta=0$, and

$s^{R}=\frac{c^{H}+\underline{U}^{R}}{p B^{H}}$

from equation (2). The proposed contract can be a candidate solution only if equation (11) holds, that is, $\frac{c^{H}+U^{R}}{B^{H^{E}}} \geq \frac{\Delta c}{\Delta B}$.

Region II: If $\alpha>0$, then $s^{R}=s^{R^{\circ}}$. Also, if $\theta=0$ then $\rho=\left(r^{V}+\mu\right) /$ $r^{R}>0$. Taking $s^{R}=s^{R^{\circ}}$ into account, equation (2) implies that

$F^{R}=\frac{B^{H}}{r^{R}}\left[\frac{\Delta c}{\Delta B}\right]-\frac{c^{H}+\underline{U}^{R}}{r^{R}}$.

The previous contract constitutes a candidate solution only if (7) and (8) hold, that is, if $F^{R} \in[0, F]$, that is, $\frac{\Delta c}{\Delta B} \geq \frac{c^{H}+U^{R}}{B^{H}}$ and $\frac{\Delta c}{\Delta B} \leq \frac{c^{H}+\underline{U}^{R}+r^{R} F}{B^{H}}$. This candidate involves $\mu=0, \rho=r^{V} / r^{R}$ and $\alpha=\left(\left(r^{R}-r^{V}\right) / r^{R}\right) p B^{H}$. (If 
$F^{R}$ defined in (15) is precisely zero, then several combinations of $\mu$ and $\rho$ are compatible with the candidate contract.)

Region III: If $\alpha>0$ and $\theta>0$, then $s^{R}=s^{R^{\circ}}$ and $F^{R}=F$. In this case, $\mu=0$. A necessary condition for this contract to be a candidate solution is that (2) holds for $s^{R}=s^{R^{\circ}}$ and $F^{R}=F$, that is, $\frac{\Delta c}{\Delta B} \geq \frac{c^{H}+U^{R}+r^{R} F}{B^{H}}$. If this inequality is strict, then the contract is indeed a candidate with associated multipliers $\rho=0, \alpha=p B^{H}$, and $\theta=r^{V}$. If it is equality, then several combinations of the multipliers are compatible with the candidate contract.

Because there is only one candidate for each possible configuration of parameters (except in the frontiers of the cases, where there are two identical candidates), the proposed candidates are indeed the optimal contracts.

Proof of Proposition 2. It follows from Proposition 1, equations (9), (10), and $F^{i} / F^{j}=f^{i} / f$ for $i, j=T, R, V$.

Proof of Corollary 1. It follows from Proposition 2.

Proof of Proposition 3. The program solved is the same as in Proposition 1, where we now consider the total financing $F$ as an endogenous variable. Given that, we come back to the notation $B^{H}(F)$ and $\Delta B(F)$. The first-order condition with respect to $F$ is

$$
\frac{\partial L}{\partial F}=\left[1-s^{R}(1-\rho)\right] p \frac{d B^{H}(F)}{d F}-r^{V}+\alpha \frac{\Delta c}{p(\Delta B(F))^{2}} \frac{d \Delta B(F)}{d F}+\theta=0 .
$$

From (12) we have that $\alpha=(1-\rho) p B^{H}(F)$. Hence, we can write (16) as

$$
p \frac{d B^{H}(F)}{d F}-r^{V}+\alpha\left[\frac{\Delta c}{p(\Delta B(F))^{2}} \frac{d \Delta B(F)}{d F}-\frac{s^{R}}{B^{H}(F)} \frac{d B^{H}(F)}{d F}\right]+\theta=0 .
$$

We use the simplifying assumption that $B^{H}(F)=b^{H} g(F)$ and $B^{L}(F)=$ $b^{L} g(F)$, we denote $\Delta b=b^{H}-b^{L}$, and we also distinguish the three regions identified in Proposition 1.

Region I: $F^{R}=0, s^{R}=\frac{c^{H}+\underline{U}^{R}}{p B^{H}(F)}, \alpha=0$ and $\theta=0$. Total capital $F$ is equal to $F^{\circ}$, where $F^{\circ}$ is characterized by equation (17) that, in this case, reduces 


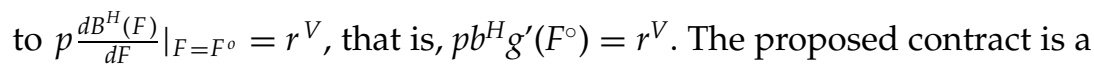
candidate solution if $\frac{c^{H}+\underline{U}^{R}}{b^{H}} \geq \frac{\Delta c}{\Delta b}$.

Region II: $\quad F^{R}=\frac{B^{H}(F)}{r^{R}}\left[\frac{\Delta c}{\Delta B(F)}\right]-\frac{c^{H}+U^{R}}{r^{R}}, s^{R}=s^{R}, \alpha=\frac{r^{R}-r^{V}}{r^{R}} \times$ $p B^{H}(F)$, and $\theta=0$. Investment $F$ is determined by (17). For the proposed functional form, the term multiplying $\alpha$ in (17) is zero when $s^{R}=s^{R^{\circ}}$. Therefore, the optimal investment is also $F^{\circ}$. The contract is a candidate solution if $\frac{\Delta c}{\Delta b} \geq \frac{c^{H}+\underline{U}^{R}}{b^{H^{2}}}$ and $\frac{\Delta c}{\Delta b} \leq \frac{c^{H}+\underline{U}^{R}+r^{R} F^{o}}{b^{H}}$.

Region III: $F^{R}=F, s^{R}=s^{R^{\circ}}, \alpha=p B^{H}(F)$, and $\theta=r^{V}$. Equation (17) becomes $g^{\prime}(F)=0$; hence, no candidate lies in this region.

In the region where $\alpha>0$ and $\theta>0$, we also have to analyze more carefully when $\frac{\Delta c}{\Delta B}=\frac{c^{H}+\underline{u}^{R}+r^{R} F}{B^{H}}$, that is, $\frac{\Delta c}{\Delta b}=\frac{c^{H}+\underline{u}^{R}+r^{R} F}{b^{H}}$, because $F$ is now an endogenous variable (hence, this case may not be degenerate). The $F$ defined as previously, together with $F^{R}=F$ and $s^{R}=s^{R^{\circ}}$, is a candidate solution for several combinations of the multipliers satisfying $\alpha=(1-\rho) p b^{H} g(F)$ and $\rho=\left(r^{V}-\theta\right) / r^{R} . \alpha \geq 0$ if and only if $\rho \leq 1$, whereas $\rho \geq 0$ if and only if $\theta \leq r^{V}$. The constraints on $\theta$ applied to the equation $p \frac{d B^{H}(F)}{d F}=r^{V}-\theta$ imply that, for the contract to be a candidate, it is necessarily the case that $F \geq F^{o}$.

The previous analysis leads to the characterization of the candidates in all the regions. The candidate is unique, except in the borders of the regions, where there are two candidates that in fact coincide. Hence, the optimal contract coincides with the unique candidate for all the parameter configurations.

Proof of Proposition 4. Out of the set of contracts that signal a good-quality project, the one that satisfies the intuitive criterion is the best for the TTO. The reason is the following: Denote by $C$ the best contract for the TTO. In order for a contract different from $C$ to be an equilibrium, it must be the case that researcher and/or VC have beliefs stating that the probability that they face a good project when they are offered $C$ is strictly smaller than 1 (otherwise, the TTO could offer $C$ and the other two participants would accept it). However, these beliefs are not "reasonable" because $C$ is a contract that the TTO would only be interested in offering if it has a good project. ${ }^{19}$

Therefore, the contract that the TTO offers in the separating equilibrium that satisfies the intuitive criterion, is the one that solves the following program: 
$\operatorname{Max}_{\left\{\left(s^{T}, F^{T}\right),\left(s^{R}, F^{R}\right),\left(s^{V}, F^{V}\right)\right\}}\left\{s^{T} p_{1} B^{H}-r^{T} F^{T}\right\}$

s.t. (2), (3), (4), (5), (6), (7), (8)

$-s^{T} p_{2} B^{H}+r^{T} F^{T} \leq 0$.

The constraints are the same as in Section 3, to which we add the ICC (18). We follow the similar steps as in the Proof of Proposition 1 to obtain $F^{V}=$ $F-F^{T}-F^{R}, s^{V}=\frac{r^{V}\left(F-F^{T}-F^{R}\right)}{p_{1} B^{H}}$, and $s^{T}=1-s^{R}-\frac{r^{V}\left(F-F^{T}-F^{R}\right)}{p_{1} B^{H}}$. In addition, in Region $I$ the PC (2) implies the ICC (1). We then rewrite TTO's problem as

$\operatorname{Max}_{F^{T},\left(F^{R, s^{R}}\right)}\left\{\left(1-s^{R}-\frac{r^{V}\left(F-F^{R}\right)}{p_{1} B^{H}}\right) p_{1} B^{H}-\left(r^{T}-r^{V}\right) F^{T}\right\}$

s.t. (2), (6), (7), (8)

$-\left(1-s^{R}-\frac{r^{V}\left(F-F^{T}-F^{R}\right)}{p_{1} B^{H}}\right) p_{2} B^{H}+r^{T} F^{T} \leq 0$.

At the optimum, (19) must be binding (otherwise, the solution would not satisfy the equation). The first-order conditions with respect to $s^{R}$, $F^{R}$, and $F^{T}$ are

$\frac{\partial L}{\partial s^{R}}=-(1-\rho) p_{1} B^{H}+\eta p_{2} B^{H}=0$

$\frac{\partial L}{\partial F^{R}}=r^{V}-\rho r^{R}+\mu-\theta-\eta r^{V} \frac{p_{2}}{p_{1}}=0$

$\frac{\partial L}{\partial F^{T}}=-\left(r^{T}-r^{V}\right)+\beta-\theta-\eta r^{V} \frac{p_{2}}{p_{1}}+\eta r^{T}=0$

From (20), $\eta=\left(p_{1} / p_{2}\right)(1-\rho)$. Then, (21) can be written as $\mu=$ $\rho\left(r^{R}-r^{V}\right)+\theta$. We show that $\mu>0$. Indeed, if $\rho=0$ then, $\eta=\left(p_{1} / p_{2}\right)$ and equation (22) becomes $\theta=\beta+\left[\frac{p_{1}}{p_{2}}-1\right] r^{T}>0$. Therefore, equation (7) holds with equality and $F^{R}=0$.

We distinguish two cases:

When $\rho=0$. In this case, as we have seen, $\theta>0$. Therefore, $F^{T}=F$ (and $\beta=0)$. Also, $\eta=\left(p_{1} / p_{2}\right)$ and constraint (19) implies $s^{R}=1-\frac{r^{T} F}{p_{2} B^{H}}$. Finally, the proposed contract (and Lagrange multipliers) constitutes a candidate solution if constraint (2) holds, that is, if

$\left[1-\frac{r^{T} F}{p_{2} B^{H}}\right] p_{1} B^{H}-c^{H} \geq \underline{U}^{R}$. 
When $\rho>0$. In this case, $s^{R}=\frac{U^{R}+c^{H}}{p_{1} B^{H}}$. Constraint (19) can now be written as

$-\left(1-\frac{\underline{U}^{R}+c^{H}}{p_{1} B^{H}}-\frac{r^{V}\left(F-F^{T}-F^{R}\right)}{p_{1} B^{H}}\right) p_{2} B^{H}+r^{T} F^{T}=0$

that, after some calculations, gives

$F^{T}=\frac{p_{2}}{p_{1} r^{T}-p_{2} r^{V}}\left(p_{1} B^{H}-\underline{U}^{R}-c^{H}-r^{V} F\right)$.

To be a candidate solution, this contract must satisfy $F^{T} \leq F$, that is,

$p_{1} B^{H}\left[1-\frac{r^{T} F}{p_{2} B^{H}}\right]-c^{H} \leq \underline{U}^{R}$.

Given that the two candidates are the unique candidates in their combination of parameters, they constitute the solution to the program.

\section{REFERENCES}

Aghion, P., M. Dewatripont, and J. Stein, 2005, “Academia, the Private Sector and the Process of Innovation," NBER Working Paper 11542.

—. and J. Tirole, 1994, "The Management of Innovation," The Quarterly Journal of Economics, 109(4), 1185-1209.

Audretsch, D. and P. Stephan, 1996, "Company Scientist Locational Links: The Case of Biotechnology," American Economic Review, 86, 641-652.

Bartelsman, E., S. Scarpetta, and F. Schivardi, 2003, "Comparative Analysis of Firms Demographics and Survival: Micro-level Evidence for the OECD Countries," OECD Economic Dept. Working Paper 348, Paris.

Bercovitz, J., M. Feldman, I. Feller, and R. Burton, 2001, “Organizational Structure as Determinants of Academic Patent and Licensing Behavior: An Exploratory Study of Duke, John Hopkins, and Penn State Universities," The Journal of Technology Transfer, 26, 21-35.

Cassiman, B. and M. Ueda, 2006, “Optimal Project Rejection and New Firm Start-ups," Management Science, 52, 262-275.

Cho, I.K. and D. Kreps, 1987, "Signalling Games and Stable Equilibria," Quarterly Journal of Economics, 103, 179-221.

Chukumba, C. and R. Jensen, 2005, “University Invention, Entrepreneurship and Startups," NBER Working Paper 11475.

Dasgupta, E. and P.A. David, 1994, “Towards a New Economics of Science," Research Policy, $23,487-521$.

Debackere, K. and R. Veugelers, 2005, "The Role of Academic Technology Transfer Organizations in Improving Industry-Science Links," Research Policy, 34, 321-342.

Dechenaux, E., B. Goldfarb, S. Shane, and M. Thursby, 2003, "Appropriability and the Timing of Innovation: Evidence from MIT Inventions," NBER Working Paper 9735. 
Demougin, D. and O. Fabel, 2007, "Entrepreneurship and the Division of Ownership in New Ventures," Journal of Economics \& Management Strategy, 16(1), 111-128.

Di Gregorio, D. and S. Shane, 2003, "Why Do Some Universities Generate More Start-ups Than Others?" Research Policy, 32, 209-227.

Etzkowitz, H., 2002, MIT and the Rise of Entrepreneurial Science, London: Routledge Press.

Franco, A.M. and D. Filson, 2000, "Knowledge Diffusion through Employee Mobility," Federal Reserve Bank of Minneapolis, Staff Report 272.

Geuna, A., A. Salter, and E. Steinmueller, eds., 2003, Science and Innovation, Cheltenham, U.K.: Edward Elgar.

Henderson, R., A. Jaffe, and M. Trajtenberg, 1998, “Universities as a Source of Commercial Technology: A Detailed Analysis of University Patenting, 1965-1988," Review of Economics and Statistics, 65, 119-127.

Hellmann, T., 2007, "Entrepreneurs and the Process of Obtaining Resources," Journal of Economics \& Management Strategy, 16(1), 81-109.

Jensen, R.A. and M.C. Thursby, 2001, "Proofs and Prototypes for Sale: The Licensing of University Inventions," American Economic Review, 91, 240-259.

Jensen, R., J. Thursby, and M. Thursby, 2003, "Disclosure and Licensing of University Inventions: "The Best We Can Do with the $S^{* *} \mathrm{t}$ We Get to Work with," International Journal of Industrial Organization, 21(9), 1271-1300.

Klepper, S., 2001, "Employee Start-ups in High Tech Industries," Industrial and Corporate Change, 10(3), 639-674.

— and S. Sleeper, 2005, "Entry by Spinoffs," Management Science, 51, 1291-1306.

Lacetera, N., 2005, "Multiple Missions and Academic Entrepreneurship," Mimeo, MIT.

Lach, S. and M. Schankerman, 2004, Royalty Sharing and Technology Licensing in Universities. Journal of the European Economic Association, 2(2-3), 252-264.

Lerner, J., 2004, "The University and the Start-up: Lessons from the Past Two Decades," Journal of Technology Transfer, 30(1-2), 49-56.

Link, A. and J. Scott, 2005, "Opening the Ivory Tower's Door: An Analysis of the Determinants of the Formation of US University Spin-off Companies," Research Policy, 34(7), 1106-1112.

Lockett, A. and M. Wright, 2005, "Resources, Capabilities, Risk Capital and the Creation of University Spin-out Companies," Research Policy, 34(7), 1043-1057.

Lowe, R. and A. Ziedonis, 2006, "Overoptimism and the Performance of Entrepreneurial Firms," Management Science, 52(2), 173-186.

Macho-Stadler, I., X. Martinez-Giralt, and D. Pérez-Castrillo, 1996, "The Role of Information in Licensing Contract Design," Research Policy, 25, 43-57.

— , and - 2001, An Introduction to the Economics of Information, 2nd edition, Oxford: Oxford University Press.

$\ldots, \ldots$, and Veugelers 2006, "Designing Contracts for University Spin-offs," Mimeo, FBBVA.

—_ _ - and, 2007, "Licensing of University Innovations: The Case of a Technology Transfer Office," International Journal of Industrial Organization, 25, 483-510.

Markman, G., P. Phan, D. Balkin, and P. Gianiodis, 2005, "Entrepreneurship and University Based Technology Transfer," Journal of Business Venturing, 20(2), 241263.

Mowery, D.C., 1998, “The Changing Structure of the U.S. National Innovation System: Implications for International Conflict and Cooperation in R\&D policy," Research Policy, 27, 639-654.

Mowery, D., R. Nelson, B. Sampat, and A. Ziedonis, 2001, “The Growth of Patenting and Licensing by U.S. Universities: An Assessment of the Effects of the Bayh-Dole Act of 1980," Research Policy, 30, 99-119. 
Nelson, R., 2001, "Observations on the Post-Bayh-Dole Rise in Patenting at American Universities," The Journal of Technology Transfer, 26, 13-19.

Nerkar, A. and S. Shane, 2003, "When Do Start-ups That Exploit Patented Academic Knowledge Survive?" International Journal of Industrial Organization, 21(9), 1391-1410.

O'Shea, R., T. Allen, A. Chevalier, and F. Roche, 2005, "Entrepreneurial Orientation, Technology Transfer and Spinoff Performance of U.S. Universities," Research Policy, 34(7), 994-1009.

Rothermael, F. and M. Thursby, 2005, "Incubator Firm Failure or Graduation? The Role of University Linkages," Research Policy, 34(7), 1076-1090.

Shane, S., 2002, "Selling University Technology: Patterns from MIT," Management Science, $48(1), 122-137$.

Siegel, D., P. Westhead, and M. Wright, 2003, "Assessing the Impact of University Science Parks on Research Productivity: Exploratory Firm Level Evidence from the UK," International Journal of Industrial Organization, 21(9), 1357-1369.

Stephan, P. E. and S. G. Levin, 1992, "Striking the Mother Lode in Science: The Importance of Age, Place, and Time," New York: Oxford University Press.

Thursby, J.G., R. Jensen, and M.C. Thursby, 2001, "Objectives, Characteristics and Outcomes of University Licensing: A Survey of Major U.S. Universities," Journal of Technology Transfer, 26(1), 59-72.

Van Looy, B., J. Callaert, and K. Debackere, 2006, "Publication and Patent Behavior of Academic Researchers: Conflicting, Reinforcing or Merely Co-existing?" Research Policy, 35(4), 596-608.

Zucker, L.G., M.R. Darby, and M.B. Brewer, 1998, "Intellectual Human Capital and the Birth of U.S. Biotechnology Enterprises," American Economic Review, 88(1), 290-306. 